\title{
Grafting of Quinones on Carbons as Active Electrode Materials in Electrochemical Capacitors
}

\author{
Thierry Brousse, ${ }^{*, a, b}$ Charles Cougnon ${ }^{*, c}$ and Daniel Bélanger ${ }^{*, d}$ \\ ${ }^{a}$ Institut des Matériaux Jean Rouxel, Université de Nantes, CNRS UMR 6502, \\ 2 rue de la Houssinière BP32229, 44322 Nantes Cedex 3, France \\ ${ }^{b}$ Réseau sur le Stockage Electrochimique de l'Energie, CNRS FR 3459, \\ 80039 Amiens Cedex, France \\ 'Laboratoire MOLTECH-Anjou, Université d'Angers, UMR CNRS 6200, 2 bd Lavoisier, \\ 49045 Angers Cedex, France \\ ${ }^{d}$ Département de Chimie, Université du Québec à Montréal (UQAM), Case Postale 8888, \\ succursale Centre-Ville, H3C 3P8 Montréal, Québec, Canada
}

\begin{abstract}
The electrochemical performance of electrochemical capacitors can be improved with electroactive quinone molecules. Systems based on redox active electrolyte as well as physisorbed and chemically grafted molecules have been investigated. In all these cases, carbon materials were used as substrate and electrode material. This short review will mainly describe work related to these systems and materials from the authors' laboratories. Nonetheless, some important studies from other research groups will be discussed.
\end{abstract}

Keywords: electrochemical capacitors, quinone, diazonium, grafting, energy storage

\section{Introduction}

The improvement of the electrochemical performance of batteries and electrochemical capacitors is currently the objective of research groups worldwide. Despite the fact that electrochemical capacitors, also known as supercapacitors, can store more energy than conventional dielectric capacitors and are characterized by a higher specific power density than batteries, approaches to increase their specific energy density are being pursued. Most of commercial electrochemical capacitors are based on two high surface area carbon electrodes and a nonaqueous electrolyte in a symmetric configuration. ${ }^{1}$ In these systems, charges are stored and delivered by the reversible accumulation and depletion of electrolyte ions at the surface of the negative and positive electrodes. When a carbon-based electrochemical capacitor is charged, the excess of charge accumulating at the positive electrode surface is compensated by adsorption of anions

*e-mail: thierry.brousse@univ-nantes.fr; charles.cougnon@univ-angers.fr; belanger.daniel@uqam.ca

This paper is part of the PubliSBQ Special Issue "IUPAC-2017" (http://publi.sbq.org.br/). from the electrolyte. The reverse process is occuring at the negative carbon electrode with cations being involved in the capacitive charge storage process. Cations and anions from the electrolyte are organized in the so-called electrochemical double-layers at the interface of the negative and positive electrodes, respectively. This purely capacitive storage is a fast process and thus insures high specific power to the device. Moreover, since chemical reactions are theoretically not occuring, electrochemical capacitors have high cycle life and long-term stability. ${ }^{2}$

Approaches that have been developed to increase the specific energy of electrochemical capacitors focused on increasing the operating voltage of the device or the capacitance of the electrodes. In comparison to commercial devices using non aqueous electrolyte and that are limited to cell voltage of up to $3 \mathrm{~V}$, room temperature ionic liquids offer the possibility to reach higher values. ${ }^{3}$ In aqueous electrolytes, where the electrochemical stability window is narrower, an alternative strategy is to use an asymmetric electrochemical capacitor based on two different electrode materials to push the limits of aqueous electrolytes. ${ }^{4}$ In this case, a voltage in the range of $2 \mathrm{~V}$ has been demonstrated 
for such device by a judicious choice of the positive and negative electrode materials. ${ }^{5}$ Unfortunately, these systems suffer from a low energy density because the voltage linearly changes from the open circuit potential, which is near zero, to the limit of the electrolyte, so that the average voltage remains low. To circumvent this difficulty, a capacitive electrode was replaced by a polarizable electrode and a hybrid system is obtained. ${ }^{6}$ Another alternative is to increase the capacity of high surface area carbon-based electrodes by organic molecules such as quinone that could sustain a reversible Faradaic reaction at the carbon electrode surface. In this case, an electrode having an intermediate behavior between a capacitive and a battery type electrode is obtained, the Faradaic charge transfer process occurring in addition to the capacitive charge storage.

In this short review, we will present a summary of studies related to quinone-modified carbons. It should be noted that quinones have been also used to develop organic rechargeable batteries ${ }^{7}$ and redox flow batteries. ${ }^{8}$ However, these two systems will not be discussed in this review. More specifically, this review will focus on electrochemical capacitors using quinone as electroactive component either as redox active electrolyte, physisorbed and chemisorbed on carbon materials.

\section{Quinones in Electrochemical Capacitors}

\subsection{Quinone-based redox active compounds}

Quinones are a class of molecules that can undergo a Faradaic reaction involving two protons and two electrons in acidic electrolyte (top) and two electrons and cationic species in alkaline electrolyte (bottom), ${ }^{9}$ as illustrated for anthraquinone (AQ) in Scheme $1 .{ }^{10}$ In these compounds, each carbonyl group can store one electron accompanied by the insertion of one cation or one proton.

Several quinones have been investigated in electrochemical capacitors, exchanging from two to four electrons. The chemical structure of the most often used quinone-based and tetraone-based compounds and their theoretical specific charge are presented in Scheme 2. ${ }^{10-17}$ The effect of the molecular structure on the electrochemical properties and the motivation for their selection will be presented below.

The main motivation for using quinones in electrochemical capacitor is to increase the specific energy density of the device by adding a redox contribution to the double layer capacitance. Figure 1 (left hand side) presents typical cyclic voltammograms for unmodified and<smiles>O=C1c2ccccc2C(=O)c2ccccc21</smiles><smiles></smiles>

Scheme 1. Redox reactions of anthraquinone in acidic (top) and alkaline (bottom) electrolytes. ${ }^{10}$<smiles>Nc1ccc(O)c(O)c1</smiles>

$1770 \mathrm{C} \mathrm{g}^{-1}$<smiles></smiles>

$1479 \mathrm{C} \mathrm{g}^{-1}$<smiles>Nc1cccc2c1C(=O)c1ccccc1C2=O</smiles>

$932 \mathrm{C} \mathrm{g}^{-1}$<smiles>Nc1ccc2c(c1)-c1ccccc1C(=O)C2=O</smiles>

$932 \mathrm{C} \mathrm{g}^{-1}$

Scheme 2. Chemical structure of electroactive molecules used for electrochemical capacitor applications. From left to right; aminocatechol, aminopyrene4,5,9,10-tetraone, amino-9,10-anthraquinone, amino-9,10-phenanthrenequinone and their respective theoretical capacity. 

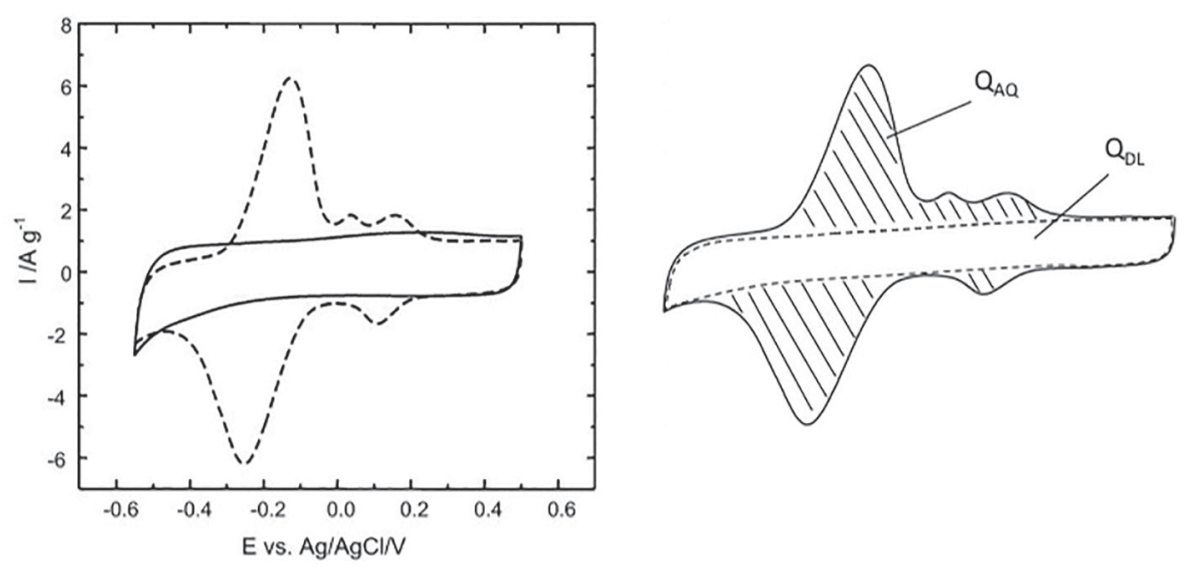

Figure 1. Cyclic voltammograms of unmodified Black Pearls (-) and anthraquinone modified Black Pearls carbon black recorded in $0.1 \mathrm{M} \mathrm{H}_{2} \mathrm{SO}_{4}$ at a scan rate of $10 \mathrm{mV} \mathrm{s}^{-1}$. The loading of anthraquinone is $11 \mathrm{wt} . \%(--){ }^{14,19}$ (Reprinted with permission from Elsevier).

anthraquinone-modified Black Pearls (BP) carbon black electrodes. The attachment of the quinone molecules (see section 2.4) allowed an increase of the store charge from $100 \mathrm{C} \mathrm{g}^{-1}$ for unmodified Black Pearls electrode to $195 \mathrm{C} \mathrm{g}^{-1}$ due to the contribution of the redox reaction (see Figure 1) of grafted anthraquinone molecules. It must be pointed out that the sum of the capacitive and Faradaic components does not lead to a capacitive-like behavior for the electrode, neither to a pseudocapacitive behavior as it is often wrongly reported in the literature. ${ }^{18}$

Interestingly, it is possible to evaluate the charge contributed by the quinone $\left(\mathrm{Q}_{\mathrm{AQ}}\right)$, represented by the hatched area on Figure 1 (right hand side), by subtracting the contribution of the double layer charge of the carbon $\left(\mathrm{Q}_{\mathrm{DL}}\right)$ from the total cyclic voltammetric charge. In these systems, the current intensity strongly changes with the potential and as it was explained in detail elsewhere, ${ }^{19}$ the capacity (in $\mathrm{C} \mathrm{g}^{-1}$ or $\mathrm{mAh} \mathrm{g}^{-1}$ ) is more appropriate to report performance, than the capacitance $\left(\mathrm{F} \mathrm{g}^{-1}\right)$. Indeed, in the case of the functionalized carbon electrode it is no longer possible to determine a capacitance since such a value will no longer be a constant all over the potential window as it was the case for the pristine carbon electrode. ${ }^{20}$

\subsection{Adsorption of quinones}

The adsorption of quinones on carbon has been investigated on materials such as basal-plane pyrolytic graphite, ${ }^{21,22}$ glassy carbon, ${ }^{23-25}$ highly-oriented pyrolytic graphite (HOPG) $)^{23,26,27}$ and carbon nanotubes. ${ }^{28}$ The adsorption of quinones on these surfaces depends on hydrophobic, dispersive, electrostatic and dipole interactions, which are influenced by the chemical nature of the carbon surface species. ${ }^{29}$ This has been recently demonstrated in studies dealing with the adsorption of phenanthrenequinone on graphene, which revealed that functionalization of graphene by introduction of hydroxyl and epoxide functionalities improved the stability of the surface molecule in comparison to pristine graphene. ${ }^{30}$

The first study reporting the use of quinone to increase the capacity of a carbon black described the immobilization of 2-nitro-1-naphthol on its surface. ${ }^{31}$ Upon cycling in an appropriate potential range, the reversible interconversion of the 1,2-naphthaquinone 1,2-naphthahydroquinone redox system in aqueous $\mathrm{H}_{2} \mathrm{SO}_{4}$ was observed. The redox contribution of the organic molecules to the overall store charge was estimated to be $126 \mathrm{C} \mathrm{g}^{-1}\left(35 \mathrm{mAh} \mathrm{g}^{-1}\right)$. Interestingly, the double layer charge of the carbon was not affected by the addition of the quinone molecules and a loss of less than $20 \%$ was noticed following 1000 charge/ discharge cycles. It should be noted that in this system the quinone molecules were only physisorbed at the carbon black surface. Therefore, it can be anticipated that covalent immobilization of quinone molecules on a carbon substrate would improve the charge retention upon cycling.

Interestingly, onion-like carbon (OLC), which consists of concentrically stacked, multi-shelled fullerenes has been shown to provide an attractive support for the stable adsorption of quinones. ${ }^{32}$ Modification by quinones allows to significantly increase the intrinsically low specific capacitance of OLC.

\subsection{Redox active electrolyte}

An approach that has attracted quite some attention is to add electroactive quinone molecules in the electrolyte, popularized as the so-called redox active electrolyte. ${ }^{33}$ The Faradaic reactions of the quinones that are occurring at the electrode surface enabled an increase of the charge storage capacity of an electrochemical capacitor based on two carbon electrodes. However, and importantly, the practical usefulness of such approach is greatly hampered by the 

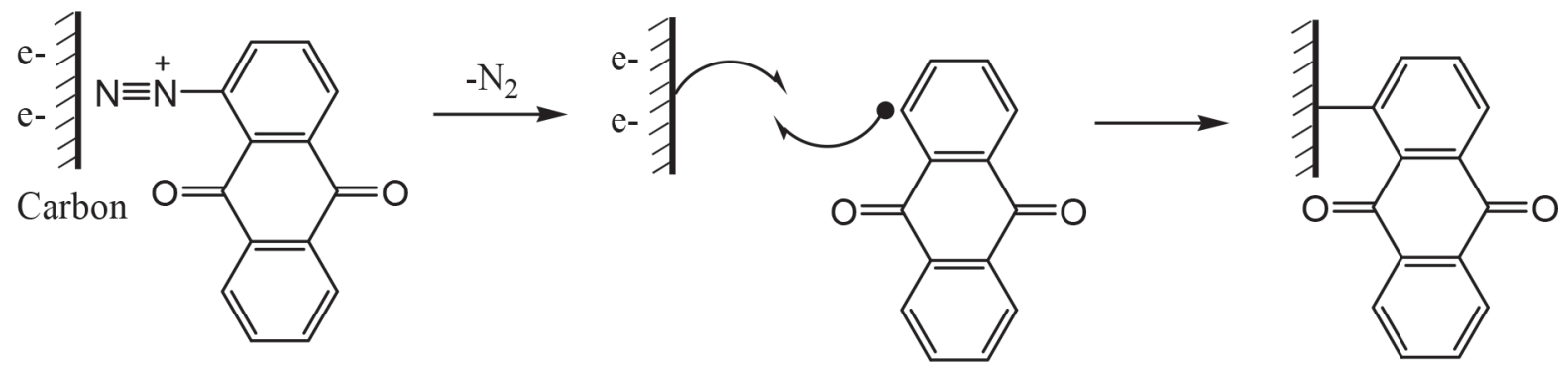

Scheme 3. Grafting reaction of anthraquinone diazonium ions with a carbon substrate by spontaneaous reduction of the diazonium cations. ${ }^{19}$

rapid decrease of the device voltage in the charged state, a phenomenon known as self-discharge..$^{34}$ Thus, finding a way to stabilize the electroactive molecules at the electrode surface or within the porous electrode would be attractive. ${ }^{35}$

\subsection{The grafting of redox groups}

Accordingly, quinone-type molecules were chemisorbed on carbon substrates by spontaneous reduction of the corresponding diazonium ions for retaining the desirable redox properties of electroactive molecules by hindering their release into liquid electrolytes. As a representative example illustrated in Scheme 3, the grafting reaction involving 1-anthraquinone diazonium cations is shown.

The same grafting reaction has been applied to attach molecules such as anthraquinone,,$^{10,11,13-15}$ chloroanthraquinone, ${ }^{12}$ catechol ${ }^{36-38}$ and phenanthrenequinone $(\mathrm{PQ})^{39}$ on various carbon substrates and more recently on a binder. ${ }^{40}$ The grafting reaction was achieved by spontaneous reduction using in situ generated corresponding diazonium ions, ${ }^{11,12,14,16}$ a reducing agent such as $\mathrm{H}_{3} \mathrm{PO}_{2}{ }^{41}$ and an acid-assisted diazotization. ${ }^{42,43}$ For these modifications, the carbon substrate (e.g., carbon powder, carbon felt) was left to react in a solution containing the diazonium ions. An alternative procedure developed to improve the grafting efficiency is based on the adsorption of 2-aminoanthraquinone on a high-surface area carbon powder, followed by the subsequent diazotization and spontaneous grafting. ${ }^{10}$ Interestingly, the loading of electroactive molecules (nitrophenyl) can be controlled (from multilayer to monolayer) by using a radical scavenger during the grafting process. ${ }^{44}$

\subsection{Energy enhancement of quinone-based supercapacitors electrodes}

The increase of the charge storage properties of a carbon electrode by a two-electron redox process of quinone molecules is not the only important parameter. A first important factor is the redox potential of grafted molecules, since the energy stored in the system can be maximized by positioning the formal potential of redox molecules near the lower or/and upper limits of the potential window. Therefore, reversible electrochemical couples with very high or very low formal potentials are preferred at the positive or negative electrode, respectively. It will be shown below that the redox potential of quinones can vary over a potential range of $1 \mathrm{~V}$, which makes them suitable for either positive or negative electrodes. This is presented schematically in Scheme 4 where the Faradaic contribution of two different electroactive molecules (shown in red and green) is superimposed on the double layer contribution of a carbon.
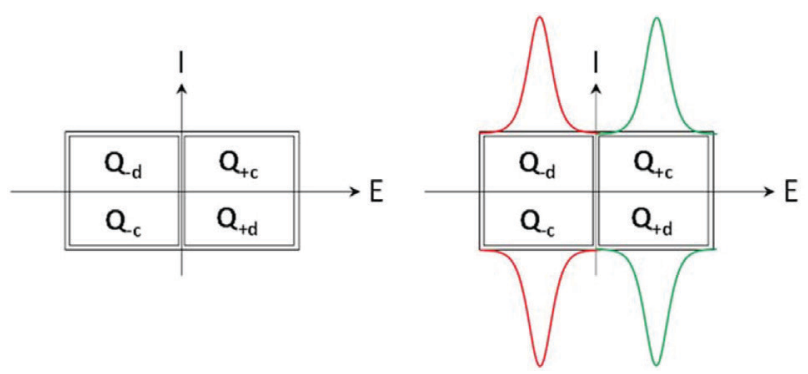

Scheme 4. Schematic cyclic voltammograms of carbon-based electrodes in the potential range swept during operation as negative and positive electrode in an electrochemical capacitor. The figure on the right hand side shows the additional Faradaic contributions of suitable molecules for the negative (red) and positive (green) electrodes.

This is especially true for dual-redox asymmetric systems where both positive and negative electrodes are modified, and for which the electrochemical storage at the level of molecules ideally should occur with high voltage swings. ${ }^{16,45-47}$ Figure 2 shows the electrochemical behavior of an asymmetric carbon-based system with redox-functionalization of both the cathode and the anode. A potential separation of $2 \mathrm{~V}$ between the two fast and reversible surface redox reactions produces an increase in specific capacity up to $51 \%$ in propylene carbonate and an energy density 2.5 times higher. ${ }^{45}$

Another important consideration illustrated in Figure 2 is related to the balance of charge between the positive and negative electrodes, which should be identical in a practical device. Figure 2 depicts the useful potential range of the 


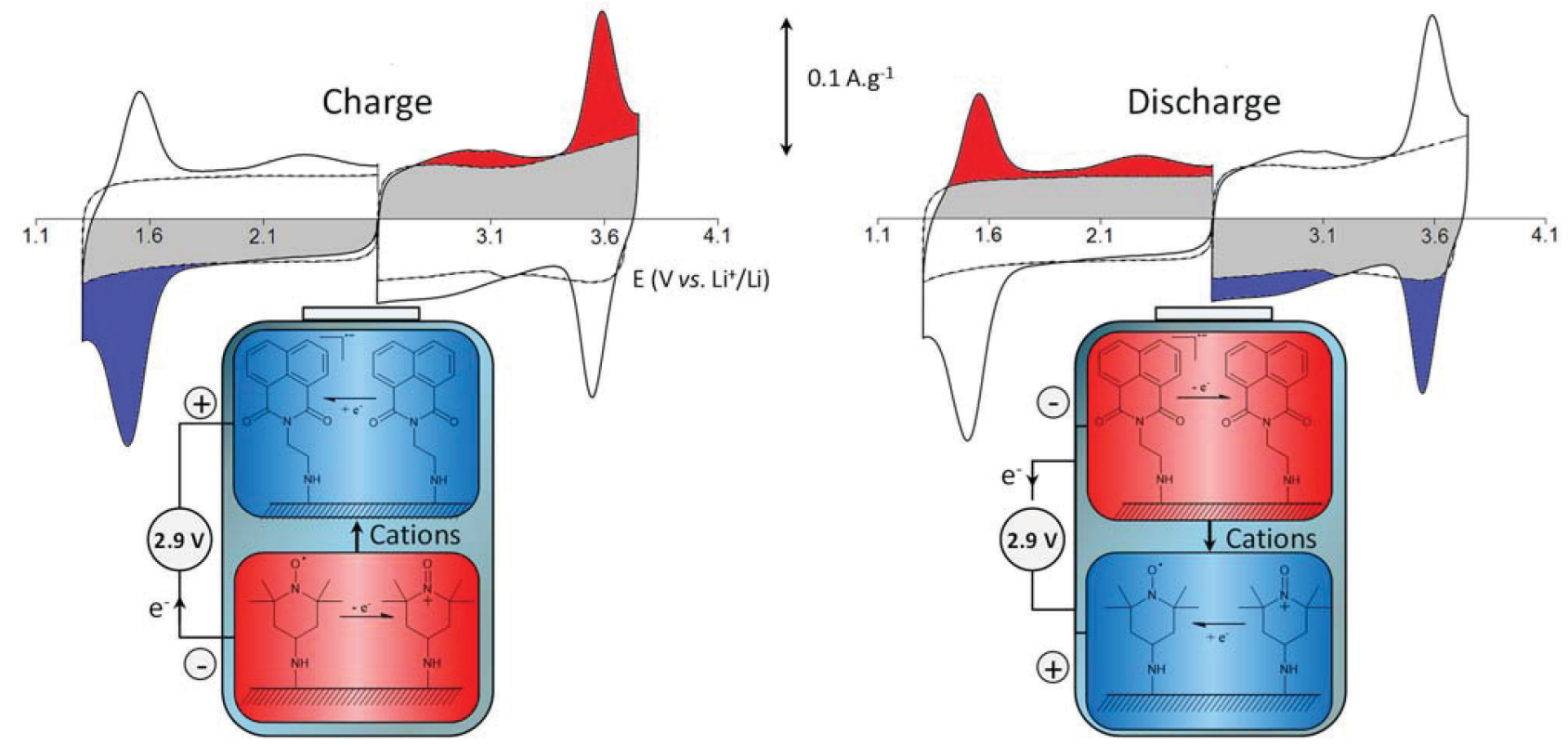

Figure 2. Illustration of a fully organic asymmetric charge storage system composed of two carbon-based electrodes modified with $N$-(2-aminoethyl)1,8-naphthalimide and 4-amino-2,2,6,6-tetramethylpiperidine- $N$-oxyl. Cyclic voltammograms were recorded in propylene carbonate $+1 \mathrm{M} \mathrm{Bu}_{4} \mathrm{NBF}_{4}$ at a scan rate of $1 \mathrm{mV} \mathrm{s}^{-1}$ (curves in dotted lines refer to unmodified carbon electrodes). (Adapted from Lebègue et al.).45

cyclic voltammogram of carbon electrodes for the negative and positive electrodes. Obviously, adding a Faradaic contribution to, for example, the negative electrode will have the consequence that a similar charge will be required for the positive electrode. This could be achieved by either increasing the mass of the positive electrode or adding, as well, a redox contribution to the positive electrode by grafting an appropriate molecule, as illustrated in Figure 2. It will be shown below that not only quinone-modified can be used as positive electrode and more specifically a metal oxide such a ruthenium dioxide ${ }^{15}$ or nickel oxide ${ }^{48}$ of an asymmetric electrochemical capacitor.

A first study reporting an increase of the energy and power densities of an electrochemical capacitor with a quinone modified electrode made use of a negative carbon fabric electrode modified by immobilization of anthraquinone by chemical reduction of 1-diazoanthraquinone with $\mathrm{H}_{3} \mathrm{PO}_{2}$ and a positive electrode consisting in the unmodified carbon fabric. ${ }^{11}$ The redox potential of the immobilized anthraquinone molecules in $1 \mathrm{M} \mathrm{H}_{2} \mathrm{SO}_{4}$ as electrolyte is $-0.1 \mathrm{~V}$ vs. saturated calomel electrode (SCE) and therefore is very well-suited for negative electrode in aqueous acid electrolyte. A $40 \%$ increase of the average capacity and a higher energy density ranging between 55 and $85 \%$ was observed as a result of quinone grafting. Subsequently, combining an anthraquinone-modified carbon fabric (Spectracarb 2225) as a negative electrode and ruthenium oxide as positive electrode in an asymmetric electrochemical capacitor yielded improved energy and power density relative to those of a symmetric ruthenium oxide device. ${ }^{15}$ Noteworthy is the fact that the anthraquinone-carbon/ruthenium oxide electrochemical capacitor requires a smaller loading of $\mathrm{RuO}_{2}(64 \%)$ than a symmetric $\mathrm{RuO}_{2}$ electrochemical capacitor. Algharaibeh and Pickup ${ }^{16}$ also reported the modification of the carbon surfaces by catechol and cyclic voltammetry measurements also revealed an increase of the specific capacity.

As mentioned above (see Figure 1), an increase of the stored charge has been observed by the covalent attachment of anthraquinone molecules on the surface of Black Pearls carbon black. Interestingly and similarly to the case when a quinone was only physisorbed on carbon, ${ }^{30}$ the double layer capacitance of the carbon black was only slightly affected, ${ }^{19}$ even if the covalent attachment of the molecules caused a major loss of the surface area of the carbon determined by nitrogen gas adsorption. This apparent discrepancy can be explained by the fact that an important fraction of the micropore volume, which was blocked by accumulation of a small amount of molecules at the pores entrance, does not contribute to the electrochemical double-layer capacitance. Due to such constriction effect, microporous carbons are particularly sensitive to grafting even when a small amount of molecules is introduced. Indeed, a drastic decrease in specific surface area of carbons is systematically observed upon grafting and most of the decrease can be related to the loss of ultramicropores. ${ }^{19}$ Due to that, recent works suggest that the porosity of the carbon must be adapted to the grafting strategy so that the activated carbon keeps its high electrolyte-accessible surface in the hybrid composite material obtained. ${ }^{49}$ 


\subsection{Stability of the Faradaic contribution over long-time cycling}

The electrochemical stability of electrodes made with quinone-modified carbon has also been examined by cyclic voltammetry and constant current charge/discharge cycling experiments, ${ }^{14}$ although this last technique is more suitable for the investigation of two-terminal devices. ${ }^{20}$ Typically, the stability profile consists of the evolution of the specific charge with the number of cycles. In acidic electrolyte, only a 17\% loss of the Faradaic charge of the quinone molecules has been observed following 10000 charge/discharge cycles. ${ }^{14}$ An important part of the loss in specific charge occured during the first 2000 cycles, due to the release of physisorbed molecules, followed by a more progressive decrease of approximately $1.3 \%$ of the Faradaic charge per 1000 charge/discharge cycles. Note that in specific cases, attached molecules can also undergo irreversible degradation under oxidation. ${ }^{50}$ Nonetheless, the specific charge of this anthraquinone modified electrode was found to be superior to that of the unmodified carbon up to about 84000 cycles.

Covalent attachment of electroactive catechol groups achieved by spontaneous reduction of in situ generated catechol diazonium ions in aqueous solution from the corresponding amine on Black Pearls carbon black ${ }^{36}$ and from acid-assisted diazotization on 9,10-phenanthrenequinonegrafted on activated carbon (Norit) ${ }^{51}$ has also been shown to improve the charge storage performance of the resulting modified carbon electrode. Indeed, due to the Faradaic contribution of the catechol units, the modified electrode can store a higher specific charge $\left(215 \mathrm{C} \mathrm{g}^{-1}\right)$ than pristine carbon $\left(130 \mathrm{C} \mathrm{g} \mathrm{g}^{-1}\right)$ between -0.4 to $0.75 \mathrm{~V}$ in $1 \mathrm{M} \mathrm{H}_{2} \mathrm{SO}_{4}$ as shown in Figure 3. The stability of the catechol-modified electrode was tested by galvanostatic charge/discharge experiments and by cyclic voltammetry over 10000 cycles. The beneficial effect of catechol groups was observed even after long time cycling. Note that recently, the catecholdiazonium cations were used under a protected form due to the strong instability of the 3,4-dihydroxybenzenediazonium ions, which evolves in solution to give side-products. ${ }^{37,52}$

The electrochemical performance of these carbonquinone composite materials are closely linked to the charge/discharge rate. Electrochemical impedance measurements of the catechol functionalized activated carbon electrode material in $1 \mathrm{M} \mathrm{H}_{2} \mathrm{SO}_{4}$ suggested that the grafting of the catechol molecules inhibits the ion diffusion to a certain extent. ${ }^{37}$ This was explained by both a reduced accessibility of the electrolyte inside the pores of the carbon material and to a higher contact resistance

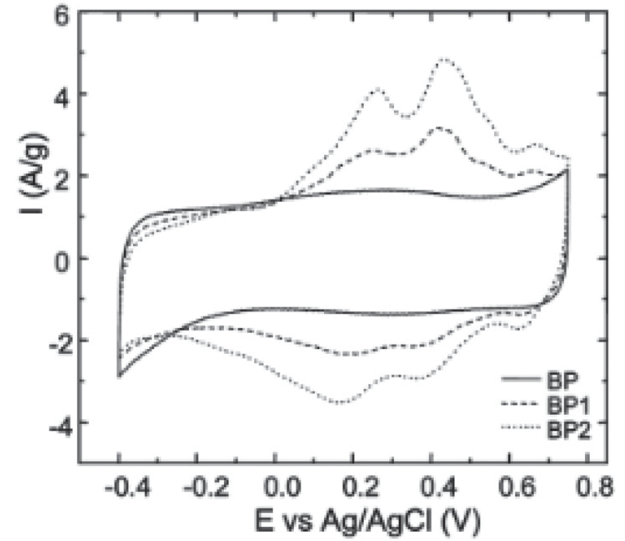

Figure 3. Cyclic voltammograms of unmodified BP (solid line) and catechol-modified carbons using aminocatechol two different concentrations of the amine precursor for the grafting reaction (dashed lines for the modification with $0.1 \mathrm{eq}$ and dotted lines for $0.2 \mathrm{eq}){ }^{36}$ (Reprinted with permission from American Chemical Society@ 2012).

between the active material and the current collector, as well as between the active material particles. This has important consequences at high charge/discharge cycling rate because in these conditions all the quinone units are not electrochemically accessible.

Anthraquinone-modified Black Pearls electrodes were also investigated in alkaline electrolyte $(1 \mathrm{M} \mathrm{KOH})$ and their stability upon potential cycling (by cyclic voltammetry) was found to be inferior to that found in acidic media. ${ }^{13} \mathrm{An}$ unconventional grafting procedure permitted a significant economy of time and solvents, yielding a slightly improved stability attributed to a smaller amount of weakly physisorbed and ungrafted molecules. ${ }^{10} \mathrm{~A}$ potential drawback of anthraquinone-modified carbon electrode is due to the close proximity of the potential of the reduction of the quinone groups with the hydrogen evolution reaction. Indeed, anthraquinone-modified carbons are characterized by a set of redox waves centered at about $-0.9 \mathrm{~V}$ in $1 \mathrm{M} \mathrm{KOH}$, which is close to the onset of the hydrogen evolution reaction. To circumvent this difficulty, electrodes prepared with phenanthrenequinone-modified carbon were investigated because they displayed electroactivity at more positive potentials along with a significant increase of the stored charge relative to the unmodified carbon. ${ }^{39,53}$ In addition to alkaline and acidic electrolyte, Norit carbon has been shown to be electroactive as well in neutral buffered electrolyte. A significant increase of the charge stored has been observed in biphthalate $(\mathrm{pH} 4)$ and phosphate $(\mathrm{pH} 7.2)$ buffers. ${ }^{53}$

The grafting of 9,10-phenanthrenequinone on Black Pearls has been shown to lead to a significant improvement of the charge storage performance of a carbon $/ \mathrm{Ni}(\mathrm{OH})_{2}$ hybrid electrochemical capacitor. ${ }^{54}$ This is illustrated in Figure 4 by the increase of the voltammetric charge of the negative carbon electrode. Interestingly, a good charge 
recovery can be maintained at relatively high cycling rate. For example, the total stored charge of a device assembled with a PQ-grafted BP negative electrode having a PQ loading of $20 \mathrm{wt} . \%$ (11.2 $\left.\mathrm{mAh} \mathrm{g}^{-1}\right)$ for a charge/discharge time of $200 \mathrm{~s}$ was found to be 2.5 times higher than that of a corresponding device using pristine $\mathrm{BP}$ carbon electrode $\left(4.5 \mathrm{mAh} \mathrm{g}^{-1}\right)$.
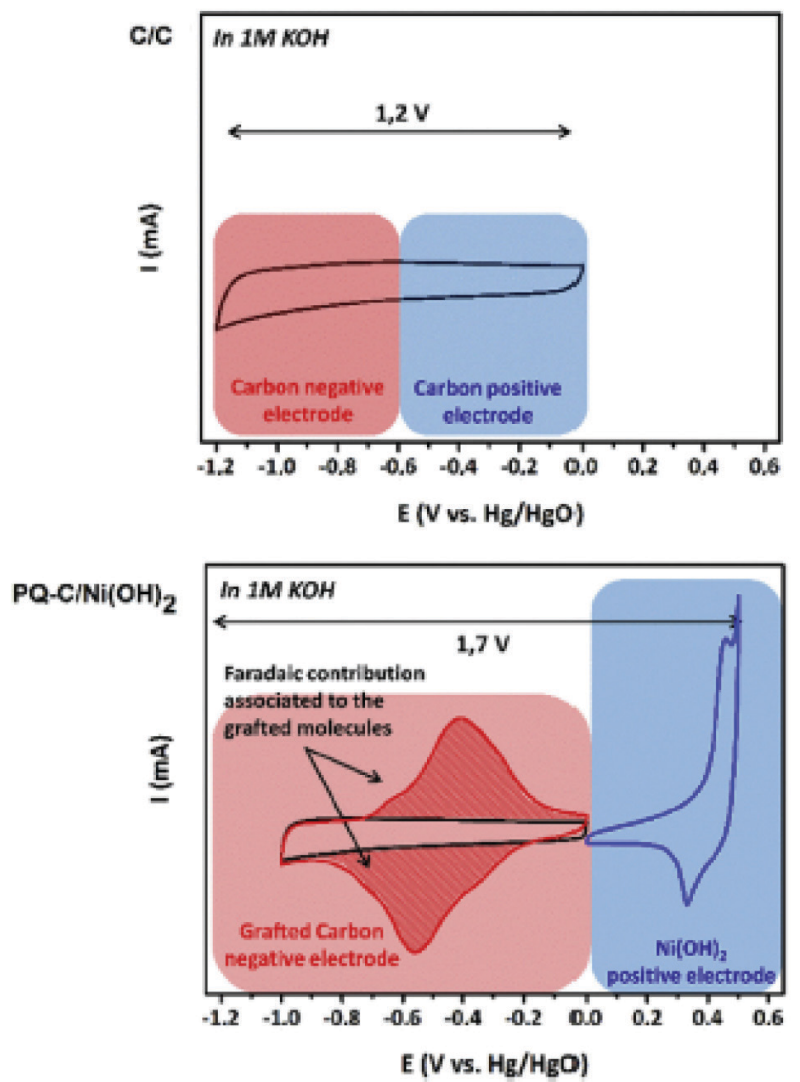

Figure 4. Schematic representation of the cyclic voltammograms of both positive and negative electrode in: a carbon/carbon symmetric (top) and both carbon and phenanthrenequinone (PQ)-modified carbon as negative electrode and $\mathrm{Ni}(\mathrm{OH})_{2}$ as positive electrode. ${ }^{54}$ (Reprinted with permission from Elsevier).

Microporous carbide derived carbon (CDC) films have been recently modified by electrochemical grafting of anthraquinone for applications in on-chip microsupercapacitors..$^{55} \mathrm{CDC}$ film electrodes can be efficiently grafted with AQ moieties for pore size larger than $2 \mathrm{~nm}$ while the CDC with smaller pore size led to a poorly functionalized electrode. As for other carbon materials, a significant increase of the charge storage properties was observed with an appropriate loading of anthraquinone molecules when cycled in alkaline electrolyte. The decrease of the Faradaic charge of the quinone molecules was attributed to electrostatic repulsion of the reduced dianionic anthraquinone species (Scheme 1) confined in narrow micropores in the alkaline media. ${ }^{55}$

\section{Conclusions}

The addition of electroactive molecules to a carbonbased electrochemical capacitors can significantly improve their charge storage properties. Organic moieties such as anthraquinone, 9,10-phenanthrenequinone and catechol, which all involve a 2-electron Faradaic redox reaction, significantly contribute in improving the charge strorage properties of the resulting carbon based electrodes. The addition of electroactive molecules to the electrolyte improved the charge being stored, but its usefulness in a practical device is limited unless the issue of selfdischarge is solved. Interestingly, molecules such as 9,10-phenanthrenequinone are known to be strongly adsorbed on carbon surfaces. Grafting of electroactive molecules by the diazonium chemistry can lead to a significant improvement of the stability of the modified carbons. Another interesting feature of quinones is related to the fact that they are electroactive in acidic, neutral and alkaline electrolytes as well as in organic media.

\section{Acknowledgments}

The authors would like to acknowledge all the co-authors of papers published on the topic of this review. This work has been supported by the Natural Sciences and Engineering Research Council of Canada (NSERC), NanoQAM, UQAM and "l'Agence Nationale de la Recherche" (ANR) of France for supporting the authors within the framework of project ICROSS.

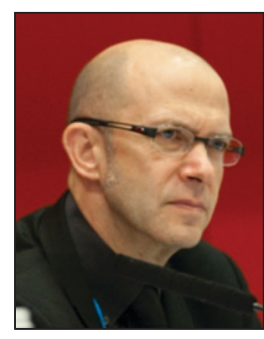

Thierry Brousse is a Professor of Materials Science at the University of Nantes. He received his PhD degree in 1991. After being a chemical engineer in a company, he joined the University of Nantes in 1994. His research at IMN focuses on innovative materials for electrochemical capacitors and related devices. He is Associate Editor for the Journal of The Electrochemical Society. He has mentored 23 PhD students. With his team as well as international collaborators, he co-authored more than 160 peer-reviewed journal publications and book chapters. He is currently vice-dean of the University of Nantes in charge of Technology Transfer.

Charles Cougnon was born in Royan, France, in 1974. He received his undergraduate education at the Universities of Poitiers and Rennes in France and obtained his PhD from the University of Rennes in 2002. Dr Cougnon joined 


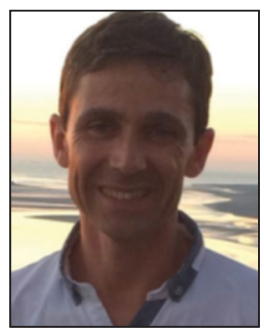

the Centre National de la Recherche (CNRS) in 2003 as Chargé de Recherche. After having exercised in Le Mans up to 2008, he moved to the Université du Québec à Montréal (UQAM) as a visiting researcher in the group of Prof D. Bélanger. On his return to France in 2009, he joined the University of Angers. His research interests are centered on modified electrodes with particular recent emphasis on the electrochemical charge storage.

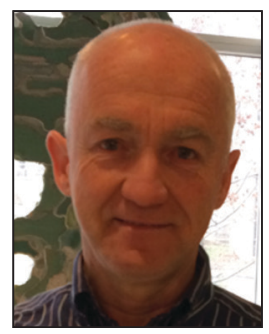

Daniel Bélanger is currently Professor and holder of a "Chaire de recherche sur les nouveaux matériaux pour les technologies de l'énergie" in the Département de Chimie de l'Université du Québec à Montréal. His current research interests in the area of electrochemistry include chemical and electrochemical modification of surfaces and electrochemical energy storage and conversion systems. He has published over 185 publications, which have been cited more than 12000 times ( $h$-index $=51$, Scopus). He is currently Associate Editor for Electrochemistry Communications.

\section{References}

1. Béguin, F.; Frackowiak, E.; Supercapacitors: Materials, Systems, and Applications; Wiley-VCH: Weinheim, 2013.

2. Conway, B. E.; Electrochemical Capacitors: Scientific Fundamentals and Technology Applications; Kluwer Academic/ Plenum Publishers: New York, 1999.

3. MacFarlane, D. R.; Forsyth, M.; Howlett, P. C.; Kar, M.; Passerini, S.; Pringle, J. M.; Ohno, H.; Watanabe, M.; Yan, F.; Zheng, W.; Zhang, S.; Zhang, J.; Nat. Rev. Mater. 2016, 1, 15005 .

4. Long, J. W.; Bélanger, D.; Brousse, T.; Sugimoto, W.; Sassin, M. B.; Crosnier, O.; Mater. Res. Bull. 2011, 36, 513.

5. Brousse, T.; Toupin, M.; Bélanger, D.; J. Electrochem. Soc. 2004, 151, A614.

6. Plitz, I.; Du Pasquier, A.; Badway, F.; Gural, J.; Pereira, N.; Gmitter, A.; Amatucci, G. G.; Appl. Phys. A: Mater. Sci. Process. 2006, 82, 615 .

7. Poizot, P.; Dolhem, F.; Energy Environ. Sci. 2011, 4, 2003.

8. Yang, B.; Hoober-Burkhardt, L.; Krishnamoorthy, S.; Murali, A.; Surya Prakash, G. K.; Narayanan, S. R.; J. Electrochem. Soc. 2016, 163, A1442.

9. Quan, M.; Sanchez, D.; Wasylkiw, M. F.; Smith, D. K.; J. Am. Chem. Soc. 2007, 129, 12847.
10. Le Comte, A.; Brousse, T.; Bélanger, D.; Electrochim. Acta 2014, 137, 447.

11. Kalinathan, K.; DesRoches, D. P.; Liu, X.; Pickup, P. G.; J. Power Sources 2008, 181, 182.

12. Le Comte, A.; Pognon, G.; Brousse, T.; Bélanger, D.; Electrochemistry 2013, 81, 863.

13. Weissmann, M.; Crosnier, O.; Brousse, T.; Bélanger, D.; Electrochim. Acta 2012, 82, 250.

14. Pognon, G.; Brousse, T.; Demarconnay, L.; Bélanger, D.; J. Power Sources 2011, 196, 4117.

15. Algharaibeh, Z.; Liu, X.; Pickup, P. G.; J. Power Sources 2009, 187, 640 .

16. Algharaibeh, Z.; Pickup, P. G.; Electrochem. Commun. 2011, $13,147$.

17. Jaffe, A.; Saldivar Valdes, A.; Karunadasa, H. I.; Chem. Mater. 2015, 27, 3568.

18. Brousse, T.; Bélanger, D.; Long, J. W.; J. Electrochem. Soc. 2015, 162, A5185.

19. Pognon, G.; Brousse, T.; Bélanger, D.; Carbon 2011, 49, 1340.

20. Balducci, A.; Bélanger, D.; Brousse, T.; Long, J. W.; Sugimoto, W.; J. Electrochem. Soc. 2017, 164, A1487.

21. Brown, A. P.; Anson, F. C.; Anal. Chem. 1977, 49, 1589.

22. Kano, K.; Uno, B.; Anal. Chem. 1999, 65, 1088.

23. McDermott, M. T.; McCreery, R. L.; Langmuir 1994, 10, 4307.

24. Sljukic, B.; Banks, C. E.; Mentus, S.; Compton, R. G.; Phys. Chem. Chem. Phys. 2004, 6, 992.

25. Vaik, K.; Sarapuu, A.; Tammeveski, K.; Mirkhalaf, F.; Schiffrin, D. J.; J. Electroanal. Chem. 2004, 564, 159.

26. Anjos, D. M.; Kolesnikov, A. I.; Wu, Z.; Cai, Y.; Neurock, M.; Brown, G. M.; Overbury, S. H.; Carbon 2013, 52, 150.

27. Sarapuu, A.; Helstein, K.; Schiffrin, D. J.; Tammeveski, K.; Electrochem. Solid-State Lett. 2005, 8, E30.

28. Sun, D.; Zhu, L.; Huang, H.; Zhu, G.; J. Electroanal. Chem. 2006, 597, 39.

29. Shi, K.; Shiu, K.-K.; J. Electroanal. Chem. 2004, 574, 63.

30. Zhou, H.; Uysal, A.; Anjos, D. M.; Cai, Y.; Overbury, S. H.; Neurock, M.; McDonough, J. K.; Gogotsi, Y.; Fenter, P.; Adv. Mater. Interfaces 2015, 2, 1500277.

31. Leitner, K. W.; Gollas, B.; Winter, M.; Besenhard, J. O.; Electrochim. Acta 2004, 50, 199.

32. Anjos, D. M.; McDonough, J. K.; Perre, E.; Brown, G. M.; Overbury, S. H.; Gogotsi, Y.; Presser, V.; Nano Energy 2013, 2, 702 .

33. Roldán, S.; Granda, M.; Menéndez, R.; Santamaría, R.; Blanco, C.; J. Phys. Chem. C 2011, 115, 17606.

34. Shul, G.; Bélanger, D.; Phys. Chem. Chem. Phys. 2016, 18, 19137.

35. Kim, H.-J.; Han, Y.-K.; Curr. Appl. Phys. 2016, 16, 1437.

36. Pognon, G.; Cougnon, C.; Mayilukila, D.; Bélanger, D.; ACS Appl. Mater. Interfaces 2012, 4, 3788. 
37. Cougnon, C.; Lebègue, E.; Pognon, G.; J. Power Sources 2015 , $274,551$.

38. Cougnon, C.; Nguyen, N. H.; Dabos-Seignon, S.; Mauzeroll, J.; Bélanger, D.; J. Electroanal. Chem. 2011, 661, 13.

39. Le Comte, A.; Chhin, D.; Gagnon, A.; Retoux, R.; Brousse, T.; Belanger, D.; J. Mater. Chem. A 2015, 3, 6146.

40. Benoit, C.; Demeter, D.; Bélanger, D.; Cougnon, C.; Angew. Chem., Int. Ed. 2016, 55, 5318.

41. Abiman, P.; Wildgoose, G. G.; Compton, R. G.; J. Phys. Org. Chem. 2008, 21, 433.

42. Delamar, M.; Hitmi, R.; Pinson, J.; Savéant, J. M.; J. Am. Chem. Soc. 1992, 114, 5883.

43. Combellas, C.; Delamar, M.; Kanoufi, F.; Pinson, J.; Podvorica, F. I.; Chem. Mater. 2005, 17, 3968.

44. Menanteau, T.; Benoît, C.; Breton, T.; Cougnon, C.; Electrochem. Commun. 2016, 63, 70.

45. Lebègue, E.; Brousse, T.; Gaubicher, J.; Retoux, R.; Cougnon, C.; J. Mater. Chem. A 2014, 2, 8599.

46. An, N.; An, Y.; Hu, Z.; Guo, B.; Yang, Y.; Lei, Z.; J. Mater. Chem. A 2015, 3, 22239.

47. Su, X.; Tan, K.-J.; Elbert, J.; Rüttiger, C.; Gallei, M.; Jamison, T. F.; Hatton, T. A.; Energy Environ. Sci. 2017, 10, 1272.
48. Eustache, E.; Frappier, R.; Lucio Porto, R.; Bouhtiyya, S.; Pierson, J. F.; Brousse, T.; Electrochem. Commun. 2013, 28, 104.

49. Lebègue, E.; Benoît, C.; Brousse, T.; Gaubicher, J.; Cougnon, C.; J. Electrochem. Soc. 2015, 162, A2289.

50. Legoupy, S.; Lebègue, E.; Cougnon, C.; Electrochem. Commun. 2016, 70, 47.

51. Lebègue, E.; Brousse, T.; Crosnier, O.; Gaubicher, J.; Cougnon, C.; Electrochem. Commun. 2012, 25, 124.

52. Nguyen, N. H.; Cougnon, C.; Gohier, F.; J. Org. Chem. 2009, 74,3955 .

53. Abbas, Q.; Ratajczak, P.; Babuchowska, P.; Le Comte, A.; Bélanger, D.; Brousse, T.; Béguin, F.; J. Electrochem. Soc. 2015, 162, A5148.

54. Le Comte, A.; Brousse, T.; Bélanger, D.; J. Power Sources 2016, $326,702$.

55. Brousse, K.; Martin, C.; Brisse, A. L.; Lethien, C.; Simon, P.; Taberna, P. L.; Brousse, T.; Electrochim. Acta 2017, 246, 391.

Submitted: November 5, 2017 Published online: February 5, 2018 